\title{
Rethinking Effective Teaching and Learning for the Design of Efficient Curriculum for Technical Teachers
}

\author{
http://dx.doi.org/10.3991/ijep.v3i1.2404 \\ T. Rüütmann and H. Kipper \\ Tallinn University of Technology, Tallinn, Estonia
}

\begin{abstract}
Technical teachers need to possess skills in at least two distinct areas: engineering discipline and the art of teaching, balancing these two areas, knowing in-action how to do it in real-life situations and for real professional purposes. Understanding student individualities and their different learning styles is one of the midpoints of teacher training. The newly designed curriculum for technical teachers makes scientifically-founded and practice-oriented teacher training possible. The aim of the study programme described is to abolish mismatches between common learning styles and traditional teaching styles. The implementation of the designed curriculum concentrates on interactive lectures and inductive teaching model. Contemporary teaching models and strategies motivate students to learn more effectively, providing future technical teachers with teaching techniques which address all learning styles.
\end{abstract}

Index Terms-Curriculum design, effective teaching, engineering pedagogy, learning styles, teaching models.

\section{INTRODUCTION}

Engineering education is a large system and it is almost impossible to predict its behaviour over far too distant future since the system parameters show a high rate of change. The knowledge is changing so fast that we cannot give students what they will need to know tomorrow. Instead, we should be helping them to develop their learning skills, so that they will be able to learn whatever they need to. If we can achieve that, we will have world-class engineers, comprising people who are innovative and resourceful.

Teaching has only one purpose, and that is to facilitate learning. Learning can occur without teaching at any loss to anyone, but teaching can, and unfortunately often does occur without learning. For our own sake as well as our students', we should make teaching and learning synonymous sides of the same coin.

Students want more real-life gumption and more initiative in learning engineering. The possibility of technical teachers is to help students to become better learners - not just in the sense of getting better qualifications, but in real-life terms, developing the set of ideas about what "learning to learn" involves, and how it can be taught. This doesn't mean that we no longer care about the content of the curriculum - content is and will be the stem of the curriculum.

While designing the curriculum across subjects and years, we should take account of could we provide cumu- lative, comprehensive mental exercises that will serve all types of students and what methodology we use in teaching engineering effectively. We must help students develop confidence to ask questions and think critically, thus becoming more confident, curious and capable learners.

The present paper will discuss the design of efficient curriculum for technical teachers providing effective teaching and learning.

\section{CURRICULUM FOR TECHNICAL TEACHERS}

\section{A. Design of the Curriculum}

The curriculum for technical teachers on Master level has been completed in 2012 at Estonian Centre for Engineering Pedagogy (ECEP) at Tallinn University of Technology (TUT). General trends in curriculum design have been used in the design of the curriculum [1]. Methodology for the curriculum design started with decisions on overall goals, learning objectives and intended learning outcomes. The curriculum was designed according to the following model: Establish Qualification Profile, Establish Admission Quality, Define Course Content, Establish the Curriculum at Macro Level, Establish the Curriculum at Micro Level, Integrate the Curriculum within the University System [1]. The Curriculum design process is a complex activity: each stage involves an iterative procedure, the output of which is evaluated before being used as a part of the input to the next stage.

A curriculum of modern technical teachers should make scientifically-founded and practice-oriented teacher training possible, so that teachers can expect to build a deeper understanding of the principles, problems and solutions associated with teaching learners in technical institutions. They should also gain greater confidence in their own skills and abilities through the use of an extended range of contemporary tools, techniques and activities.

Specific teaching and learning strategies will be required if the objectives are to be successfully obtained, and this requires an understanding of the complexity of learning. In the process of the curriculum and syllabi design the following principles have been taken account of:

- How could teaching help students to learn effectively? How can we teach students to employ effective learning strategies?

- How contemporary teaching methods could be used in teaching engineering? Students, future technical teachers should experience contemporary teaching 
methods and models, and analyse their own learning relevantly.

- Students' differences should be taken account of in teaching engineering. How much students learn is determined by the match between their learning style and instructor's teaching style. To maximise student learning, we have to work with our teaching style, methods and models.

- Technical teachers must teach students to ask questions and think critically in the context of the relevant field of engineering and engineering pedagogy.

\section{B. Sructure of the Designed Curriculum}

The newly designed curriculum provides education in Engineering Pedagogy for technical teachers on Master level - technical teachers in the amount of 120 ECTS (European Credit Transfer System) credits. The curriculum is based on International Society for Engineering Education (IGIP) Recommendations for Studies in Engineering Pedagogy Science. The proven IGIP engineering education curriculum is based on the knowledge of traditional pedagogy in philosophy and the liberal arts but respects the particular character of the technician and the analytical-methodological approach in the fields of engineering science.

Students with at least Bachelor degree in engineering speciality will be admitted to the pilot programme from September 2013. The aim of the curriculum is to give scientifically based, consistent education to persons already possessing Bachelor degree in engineering or respondent education, to enable them to teach engineering competently, effectively and creatively at vocational schools, gymnasiums, colleges or universities; to design an idiosyncratic system of teaching for technical teachers, taking into consideration the basics of Educational Psychology and Engineering Pedagogy Science in the study process of teaching theory and practice.

According to chosen educational level, acquired education affords prerequisites for a work as:

- Technical teacher at upper secondary level (gymnasium) teaching optional technology courses or physics, mathematics or chemistry.

- Technical teacher at vocational schools, teaching engineering speciality subjects.

- Engineering educator at the level of higher education.

Students may choose between 8 specialisations depending on their acquired engineering education:

- Civil Engineering.

- Power Engineering.

- Geological Technology.

- Information and Communication Technology.

- Chemical and Material Technology.

- Logistics.

- Mechanical Engineering.

- Technical Physics and Mathematics.

The structure of the designed curriculum is presented in Table 1 . As it could be seen the amount of the curriculum is 120 ECTS credits, the nominal study period is 2 years.

Education is completed by defending Master Thesis or by passing the final Master Degree Examination. The final examination consists of the presentation and discussion of the candidate's portfolio, presentation of a micro-lesson and an examination interview. Students who have fulfilled the curriculum and passed the final examination are awarded a degree of Master of Arts in Education (MA), and may apply for a qualification of an international engineering educator from IGIP.

TABLE I. STRUCTURE OF THE CURRICULUM

\begin{tabular}{|c|c|}
\hline Model/Subjects & $\begin{array}{l}\text { ECTS } \\
\text { credits }\end{array}$ \\
\hline \multicolumn{2}{|l|}{ Basic Studies 30 ECTS } \\
\hline $\begin{array}{l}\text { Compulsory Subjects: Research in Education; Cognition } \\
\text { and Action; Educational Psychology; Foundational } \\
\text { Education; Pedagogical Communication }\end{array}$ & 30 \\
\hline \multicolumn{2}{|l|}{ General Studies 25 ECTS } \\
\hline $\begin{array}{l}\text { Compulsory Subjects: Teaching Technology, Media and } \\
\text { E-Learning; Working with Projects: Curriculum Design: } \\
\text { Laboratory Didactics and Methodology; Ethics and } \\
\text { Multicultural Learning Environment; Human Commu- } \\
\text { nication and Academic Writing for Technical Teachers; } \\
\text { Engineering Pedagogy Science in Theory and Practice }\end{array}$ & 23 \\
\hline $\begin{array}{l}\text { Optional Subjects: Product Development and Innova- } \\
\text { tion; Standards and Quality; Information Technology; } \\
\text { Academic Foreign Language }\end{array}$ & 3 \\
\hline \multicolumn{2}{|l|}{ Core Studies 12 ECTS } \\
\hline $\begin{array}{l}\text { Optional courses in Methodology and Didactics accord- } \\
\text { ing to the chosen school level }\end{array}$ & 12 \\
\hline \multicolumn{2}{|l|}{ Teaching Training Practice 15 ECTS } \\
\hline \multicolumn{2}{|c|}{$\begin{array}{c}\text { Engineering Speciality Optional Studies in chosen engineering } \\
\text { specialisation } 12 \text { ECTS }\end{array}$} \\
\hline \multicolumn{2}{|l|}{ Optional Free Subjects 6 ECTS } \\
\hline \multicolumn{2}{|l|}{ Master Thesis or Master Degree Examination 20 ECTS } \\
\hline
\end{tabular}

The curriculum for technical teachers at ECEP has been concentrating on interactive lectures and inductive teaching methods. Different active methods, suitable for teaching engineering, are taught in interactive lectures, mainly in the subject of the Engineering Pedagogy Science in Theory and Practice. These methods motivate students to learn more effectively, providing teaching techniques which address all learning styles.

\section{ANALYSIS OF EFFECTIVE TEACHING AND LEARNING}

\section{A. The Complex of Effective Teaching and Learning}

Technical teachers have to be competent in the relevant field of engineering and subject they teach. But they also need to know how to teach effectively, the core knowledge is to know in-action how to do it in real-life situations and for real professional purposes.

There are four teaching-learning scenarios in teaching engineering [2]:

- Teaching is ineffective, students are ineffective, and leaning is therefore minimal. In this case teacher gives students just an outline material and students study it by rehearsing facts. With the combination of weak teaching and weak learning skills students learn a little.

- Teaching is effective, students are ineffective learners, and learning is good. Teacher provides a framework for selecting and noting key-points, a chart for 
organising selected points, a list of important associations and practice questions to foster regulation. Although students do not know how to apply effective learning strategies on their own, instruction is so good that it compensates for students' weak learning. Good teaching triumphs over weak learning. Students soar for success in spite of their poor learning skills.

- Teaching is ineffective, students are effective learners, and learning is good. Teacher gives students just an outline of the material. Students take copious notes, convert the outline to a chart, generate associations, and test themselves over the facts and relationships inherent in the material. Learning strategies are so good that they compensate for ineffective teaching. Good learning triumphs over weak teaching. Students soar for success in spite of ineffective teaching.

- Teaching is effective, students are effective learners. Learning is maximal. With the best of both worlds, students soar to success and beyond.

Teaching and learning both can be effective or ineffective. Teachers often teach engineering in ways that limit learning [2] and students employ weak and unproductive learning strategies. Teaching and learning system is broken, because teachers are not taught to present material in ways that help students and take account of their learning style. Teachers are not taught how to design instruction that ensures learning, how to teach for deep understanding. Teachers often teach the way they remember their teachers have taught them.

Many students, on the contrary, do not know how to learn. They have spent half of their waking hours at school, but they were never taught how to learn effectively taking account of their learning style, how to take a quality set of notes, manage time, foster motivation, organise notes or create associations. Teachers usually focus on the product of learning and ignore the process, consequently, students learn some content but there is no deep understanding.

Since the final destination of teaching is student learning, there are two ways to improve learning by:

- Improving teaching - helping teachers present their material so effectively that students learn in spite of their weak learning strategies. In this case student learning depends on teacher effectiveness.

- Helping students to acquire effective learning strategies, so they can learn even when teaching is ineffective.

It is possible for teachers to take both roads simultaneously: teach effectively and teach students how to learn. First teachers should present material in a way that students cannot help but learn - helping students to select key ideas and concepts, organise them, show connections, create associations, think critically in front of the class and regulate learning - and they should teach students how to do it on their own. In order for students to learn how to learn, they need practice applying strategies to real coursework. Teachers can help students to select by providing notes, frameworks and cues, encouraging reconstruction.

Learning strategies are learned best when embedded into content teaching, using four simple steps [2]:
- Introduce the strategy by modelling and describing it.

- Sell the strategy by telling why it works.

- Generalise the strategy by telling where else it is helpful.

- Perfect the strategy by providing practice opportunities.

The key to memorizing and problem solving is organisation. Usually students learn one idea at a time. Information in engineering education is often presented to students in blocks of texts, in outlines, in lists, in bite-size pieces thus hiding symbiotic relationships, the completed puzzle, the structure, similarities and differences.

Representations (illustrations, matrices, sequences, hierarchy, etc) should be used to improve teaching and helping students organise information.

Learning depends on selecting important material and organising it, but teachers should also associate presented information by providing examples and non-examples, and raising association questions (How are these thing alike/different? What is the association between structure and function? What common categories cut across the topic? What do we know about this? Why? What if?).

For deep understanding students must select, organise, and associate information, but they should also regulate by monitoring and assessing learning. Teachers can help students by providing objectives, rubrics, timelines and practice test, but also conduct error tests [3].

In teaching engineering there is also a tendency to ask questions as though they are rice thrown at a wedding. Throwing out lots of questions makes the teacher feel good. These questions often do little to support deep understanding but the answers that come back make it feel productive. Carefully focused questions, in the other hand, make all the difference. Focused questions are aimed at a particular target. The target is determined by the stage of the instruction and the nature of understanding to be supported. There must be relevant, accessible prior knowledge or it must be provided or constructed; the relationships must be known or capable of construction; the relevant and irrelevant must be discriminated and a need to inference has to be recognised. The target is likely to be pre-requisite knowledge. Questions, therefore, are aimed at stimulating recall of pre-requisites and practising it. They also serve to indicate where prior knowledge is deficient and needs to be improved. The nature of the question matches the immediate goal of instruction. Teachers often ask mainly factual questions, regardless of the goal [3].

Effective teachers phrase questions clearly, avoid runon questions, and specify the conditions for the response. They probe for clarification and encourage students to critical thinking. Although responses are acknowledged, praise is used with discretion. Many questions require rote memory for a correct response. Perhaps, because questions that require recitation of facts take less time, teachers sometimes avoid asking higher-level questions.

Merely asking questions does not cause students to think. But higher-level question invite and encourage higher levels of critical thinking in students. Furthermore, it appears that if teachers systematically raise the level of their questioning, students raise level of their responses correspondingly. This requires a carefully planned questioning strategy. Through appropriate questioning student 
curiosity is fostered. Curiosity is affective dimension of learning and it deals with motivation [3].

Questioning is a primary tool in teaching engineering for leading students into higher order thinking. Students should be asked more how, why, or what do you suppose questions, not only what questions. Knowledge requires memory only, repeating information exactly memorised the what. Comprehension, however, calls for rephrasing, rewording and comparing information. Application requires the learner to apply knowledge and understanding to determine an appropriate, correct answer. Analysis asks students to identify motives or causes, draw conclusions and determine evidence. Synthesis leads students to make predictions, produce original communications, or solve problems. Evaluation causes students to make judgements, offer and support opinions.

Through a cleverly planned questioning strategy, a technical teacher can creatively lead students through the cognitive taxonomy of thinking. Carefully devised questions facilitate the observation, communication, comparison, ordering, categorisation, relating, inferring from, and application of information. Beginning with what or the recall questions, in teaching engineering a teacher should lead from the knowledge base into understanding and from understanding into practical application, from application into a more careful analysis, and after analysis into a synthesis or a reassembling of the notion in a new and different way. This entire process can then be assessed and judged as having merit, quality, or worth, teaching students to evaluate all ideas on a consistent set of criteria.

Technical teachers could promote observation by directing students like "tell us what you see" or "list the properties that are apparent in the sample”, by asking questions like: "What are the dominant characteristics of this subject?”, "What is the object's size and shape?” For comparing information, the scientific thought process that deals with similarities and differences, technical teacher should lead the analytic questioning: "How are these alike?", "How are these different?", "Which comes first, second, third?", "On what basis would you group these ideas or objects?", "What is a different way in which these characteristics can be clustered?". Following analytic questions, synthesis questions should be asked: "Use the information you have learned to design something new". The final element of reason and thought would be leading students into evaluation by asking for example "Which experimental design was the best? Why?" Related to evaluation is the process of inferring, concluding and deciding. This is the scientific thinking process that deals with ideas remote in time and space: "What can be inferred from this information?", "Predict the outcome and give evidence to support your prediction”, "Under what conditions might we extrapolate from this observed information and believe that a similar reaction could occur under a different circumstance?”.

Schools have typically neglected teaching for thinking, and transfer thinking operations from one subject to another and to real life. Emphasis has been on information acquisition and low-level content. Students need to do more than learn information. Thinking skills and processes need to be learned, as does the ability to use these in a variety of contexts. If teaching and learning are to be authentic, teachers need to teach for thinking. One of powerful strategies for teaching for critical thinking and deep understanding is questioning.

\section{B. Deductive and Inductive Teaching Model}

The dominant teaching model in engineering is deductive, where a teacher takes full control of the transmission of knowledge - this model regards a teacher as an expert and students as a group of novices. The process of learning, thinking, and doing sends a powerful message that students receive as information about how engineers work. Having no other experience, they take the classroom to represent profession. Numerous textbook problems they have to solve do not sufficiently challenge students to move to a deeper level understanding and skill of analysis that helps towards critical thinking. Exams generally assess students' skill in using engineering tools and students are expected to show technical skill in applying mathematical formula to a given problem. Learning to use concepts to analyse real-world problems is an important goal in teaching engineering, but students have very little opportunity to develop these skills today.

Inductive teaching is one way to help students learn to use the fundamental concepts for problem solving teacher focuses on cases that students could work on to help them develop an understanding of the phenomenon that these cases represent before a principle is introduced [4].

A teacher might begin with a problem, such as how to hold a $2 \mathrm{~kg}$ weight using a piece of paper and paper clips and ask the students to figure out the fundamental elements which are critical to the problem. Based on their knowledge and experience, students attempt to explore possible cases, developing a sense of awareness of the relevant key elements - load, stress and strength. They begin their concept-formation based on the phenomenon observed. Teacher introduces new cases and along with students identifies their fundamental elements, using formulas, equations, graphs or diagrams as tools in helping students refine their concept formation.

We should recognize that students learn best when they perceive a need to know the material being taught. We recommend to start with realistic complex problems, let students establish what they know and what they need to find out, and then guide them in finding it out by providing a combination of resources (which may include interactive mini-lectures and integrated hands-on or simulated experiments) and guidance on performing library and Internet research. This is inductive teaching and has a number of variations, including problem-based learning, project-based learning, guided inquiry, discovery learning, and just-in-time teaching [4].

According to Prince and Felder [4] the Inductive Model is an umbrella term that encompasses a range of instructional methods, including inquiry learning, problem-based learning, project-based learning, case-based teaching, discovery learning, and just-in-time teaching. These methods have many features in common, besides the fact that they all qualify as inductive. They are all learnercentred they impose more responsibility on students for their own learning than the traditional lecture-based deductive approach does. They are all supported by research findings that students learn by fitting new information into existing cognitive structures. The methods almost always involve students discussing questions and solving problems in class with lot of collaborative or cooperative learning. 
The Inductive Model is designed to help students reach two types of learning objectives:

- For students to acquire deep and thorough understanding of specific and well-defined topics.

- To develop students' critical thinking abilities. Students try to find patterns in the new information and with the teacher's guidance they construct a thorough understanding of the topics and learn to make and assess conclusions based on evidence.

Differences between these two described models are: teacher's early introduction of context, thus encouraging students to think in real terms and potential of students to be more reflective about their own learning, as the learning experience becomes more iterative and less linear. Although the inductive model can be messy and challenging, its impact on student learning can be enormous.

\section{Teaching and Learning Styles}

Learning styles are characteristic cognitive, affective, and psychological behaviours that serve as relatively stable indicators of how learners perceive, interact with, and respond to the learning environment. Students learn best when instruction and learning context match their learning style.

Understanding students' different learning styles is one of the midpoints of technical teacher training. The aim of the designed curriculum for technical teachers is to abolish mismatches between students' common learning styles and traditional teaching styles of technical teachers and make teaching in engineering more effective, to equip technical teachers with the skills associated with every learning style category, regardless of the students' personal preferences, since they will need all of those skills to function effectively as professionals.

Technical teachers should attempt to improve the quality and efficiency of their teaching, which in turn requires understanding the learning styles of engineering students and designing instruction to meet them. The problem is that two students are never alike. They have different backgrounds, strengths and weaknesses, interests, ambitions, senses of responsibility, levels of motivation, and approaches to studying.

According to Richard M. Felder [5] students learn in many ways - by seeing and hearing; reflecting and acting; reasoning logically and intuitively; memorising and visualising; drawing analogies and building mathematical models. Teachers' teaching methods also vary. Some teachers lecture, others demonstrate and discuss; some focus on principles and others on applications; some emphasise memory and other understanding. How much a student learns in a class is governed by student's ability and prior preparation, but also by compatibility of student's learning style and the teacher's teaching style.

At ECEP teaching methodology and models of designed curriculum for technical teachers are based on Felder-Silverman learning and teaching style model for engineering education [5]. The future technical teachers get acquainted with following different learning styles of engineering students: sensing/intuitive learners (sensing learners like facts, data, and experimentation; intuitive students prefer principles and theories); visual/auditory learners (visual learners prefer sights, pictures, diagrams, symbols; auditory learners - sounds and words); induc- tive/deductive learners - induction is a reasoning progression from particulars (observations, measurements, data) to generalities (governing rules, laws, theories); deduction proceeds in the opposite direction; active/reflective learners (active experimentation involves doing something with the information: discussing it or explaining or testing; reflective observation involves examining and manipulating the information introspectively); sequential/global learners (sequential learners learn in a logically ordered progression, global learners learn in fits and starts: they may be lost for days or weeks, until suddenly they "get it”).

According to Richard M. Felder [6] an engineering student's learning style may be defined by the following methodology, answering to five questions:

- What type of information does the student preferentially perceive: sensory (external) -sights, sounds, physical sensations, or intuitive (internal) - possibilities, insights, hunches?

- Through which sensory channel is external information most effectively perceived: visual - pictures, diagrams, graphs, demonstrations, or auditory words, sounds?

- With which organization of information is the student most comfortable: inductive -facts and observations are given, underlying principles are inferred; or deductive -principles are given, consequences and applications are deduced?

- How does the student prefer to process information: actively - through engagement in physical activity or discussion, or reflectively - through introspection?

- How does the student progress toward understanding: sequentially - in continual steps, or globally - in large jumps, holistically?

Mismatches exist today between common learning styles of engineering students and traditional teaching styles of engineering professors. Most engineering students are visual, sensing, inductive, and active, and some of the most creative students are global, but most engineering education is auditory, abstract (intuitive), deductive, passive, and sequential. In consequence students become bored and inattentive, do poorly tests, get discouraged, and in some cases change to other curricula or drop out of school [8].

Analysis of the students' learning styles at ECEP has been carried out according to above introduced methodology created by Richard Felder [8]. As the result of the analysis, the future technical teachers, students studying at ECEP, were classified as follows: of the analysed 68 students, $61 \%$ were classified as active learners, 39\% were classified as reflective learners, $64 \%$ were sensing learners, $30 \%$ were intuitive learners, $87 \%$ were visual learners, $15 \%$ were verbal learners, 55\% were sequential learners and 34\% were global learners [9].

As the results of the analysis present, 64\% of students were sensors, while traditional engineering instruction is usually oriented toward intuitive learning, emphasizing theory and mathematical modelling. $87 \%$ of the students were visual learners, but most of engineering instruction is overwhelmingly verbal, emphasizing written explanations and mathematical formulations of physical phenomena. $61 \%$ of the students were active, while most engineering courses other than laboratories rely on lectures as the 
principal method for transmitting information. 55\% of the students classified themselves as sequential learners and as traditional engineering education is heavily sequential, relevantly there is no mismatch between students' learning style and instructors' teaching style in this case. 34\% of students were global learners. According to Richard Felder [8] global learners are multidisciplinary thinkers with broad vision. Unfortunately, traditional engineering education is sequential and does little to provide students with global learning style to meet their needs.

As it could be seen from the results of the analysis, in engineering education there is a great mismatch between students' learning styles and instructors' teaching methods. Thus it is of high importance for technical teachers to make instruction more effective to abolish these mismatches, and taking account of them.

At ECEP students attending the designed curriculum are taught how in their future profession as technical teachers it is possible to help their students to learn more effectively. Accordingly to Felder's methodology [7] active learners should try to study in a group in which the members take turns explaining different topics to each other. They will always retain information better if they could find ways to do something with it. Reflective learners in turn should not simply read or memorize the material, but stop periodically, review what they have read and think of possible questions or applications. Reflective learners might find it helpful to write short summaries of readings or class notes in their own words. Sensing learners remember and understand information best if they can see how it connects to the real world - they should ask their instructor for specific examples of concepts and procedures, and find out how the concepts apply in practice. Intuitive learners should ask their instructor for interpretations or theories that link the facts, or try to find the connections themselves. Visual learners should try to find diagrams, sketches, schematics, photographs, flow charts, or any other visual representation of the course material that is predominantly verbal, prepare a concept map by listing key points, and colour-code notes. Sequential learners should outline the lecture material in logical order. Global learners need the big picture of a subject they should skim through the entire chapter to get an overview and thus study more effectively.

Although the diverse styles with which students learn are numerous, the inclusion of a relatively small number of techniques as an instructor's teaching tools should be sufficient to meet the needs of most or all of the students in any engineering class. The techniques and suggestions presented below should serve this purpose in any case.

The following recommended teaching techniques by Richard Felder [8] suitable for engineering education to address all learning styles serve as the basis of instruction at ECEP to future technical teachers:

- Motivate learning. As much as possible, relate the material being presented to what has come before and what will to come in the same course, to material in other courses, and particularly to the students' personal experience (inductive/global).

- Provide a balance of concrete information (facts, data, real or hypothetical experiments and their results) (sensing) and abstract concepts (principles, theories, mathematical models) (intuitive).
- Balance material that emphasizes practical problemsolving methods (sensing/active) with material that emphasizes fundamental understanding (intuitive/reflective).

- Provide explicit illustrations of intuitive patterns (logical inference, pattern recognition, generalization) and sensing patterns (observation of surroundings, empirical experimentation, attention to detail), and encourage all students to exercise both patterns (sensing/intuitive).

- Follow the scientific method in presenting theoretical material. Provide concrete examples of the phenomena the theory describes or predicts (sensing/ inductive); then develop the theory or formulate the mod (intuitive/inductive/ sequential); show how the theory or mod can be validated and deduce its consequences (deductive/sequential); and present applications (sensing/deductive/sequential).

- Use pictures, schematics, graphs, and simple sketches liberally before, during, and after the presentation of verbal material (sensing/visual). Show films (sensing/visual.) Provide demonstrations (sensing/visual), hands-on, if possible (active).

- Use computer-assisted instruction - sensors respond very well to it (sensing/active).

- Do not fill every minute of class time lecturing and writing on the board. Provide intervals - however brief - for students to think about what they have been told (reflective).

- Provide opportunities for students to do something active besides transcribing notes. Small-group activities that take no more than five minutes are extremely effective for this purpose (active).

- Assign some drill exercises to provide practice in the basic methods being taught (sensing/active/sequential) but do not overdo them (intuitive/reflective/ global). Also provide some openended problems, questions and exercises that call for analysis and synthesis (intuitive/reflective/global).

- Give students the option of cooperating on homework assignments to the greatest possible extent (active). Active learners generally learn best when they interact with others; if they are denied the opportunity to do so they are being deprived of their most effective learning tool.

- Applaud creative solutions, even incorrect ones (intuitive/global).

- Talk to students about learning styles, both in advising and in classes. Students are reassured to find their academic difficulties may not all be due to personal inadequacies. Explaining to struggling sensors or active or global learners how they learn most efficiently may be an important step in helping them reshape their learning experiences so that they can be successful (all types).

The idea is not to use all the above described techniques in every class but to choose several that look feasible and try them, keeping the ones that work, dropping unsuitable, and trying some more in the next course. In this way a teaching style that is both effective for all students and comfortable for technical teachers will effect positively on the quality of engineering students' learning. 
The point of taking account of different learning styles in teaching engineering is not to determine each student's preferred instructional approach and teach exclusively in that manner. It is rather to "teach around the cycle," making sure that every style is addressed to some extent in the instruction. If this is done, all students will be taught in a manner that addresses their preferences part of the time, keeping them from becoming so uncomfortable that they cannot learn, and requires them to function in their less preferred modes part of the time, helping them to develop skills in those modes. At ECEP Felder-Silverman learning and teaching style model for engineering education is used as the basis for the instructional design.

\section{DISCUSSION}

Expert teachers generally are comfortable with wide range of teaching strategies, varying them skilfully according to the learning task and learners' needs [10]. Some of these are general strategies, such as skilled questioning, clear communication, organizing lessons, and effective feedback, starting lessons with a review and ending with closure, applicable in all teaching situations. Other, more explicit strategies, called teaching models, are grounded in learning and motivation theory and designed to reach specific learning objectives. All of them are designed to help students develop a deep understanding of the topics they study and improve their critical-thinking abilities [3].

There is no sense to stop a lecture and wait for students' questions. Ask questions periodically (What next? What could be wrong? What could go wrong? What should the solution look like? What have we assumed in writing this formula? How can I correct the problem? How could I have avoided it?) [3].

More effective in teaching engineering is to involve students actively, thus finding out what the students have not understood and only then the teacher answers arisen questions. The wide array of effective active methods in lecture should wipe off the notion that good teachers are born and not made [11]. Once a teacher incorporates students' active breaks into the lecture, an interactive lecture is given, during which students are in some way interacting with the material for brief, controlled period of time. A teacher must carefully time-control the studentactive breaks, thus keeping students focused on the task. Just five minutes of activities in a 50-minute class can be enough to keep the students awake and attentive for the remaining 45 minutes of lecturing.

Active learning exercises in interactive lectures address a variety of objectives: recalling prior material, responding to questions, problem solving, explaining written material, analytical, critical, and creative thinking, generating questions and summarizing.

At ECEP several tested interactive methods, suitable for teaching engineering are taught to the future technical teachers. The students practice holding interactive lectures in seminars and workshops. Teaching methods fostering active and long-term engagement with learning tasks emphasizing conceptual understanding are used in the study programme for technical teachers at ECEP [9]. The following most frequently used interactive teaching methods are taught during the study programme:

- Pair and compare - students pair off with their neighbours and compare lecture notes filling in what they have missed, thus reviewing and processing reflectively the lecture content. Time: 2-3 minutes.

- Solve a problem - students solve a problem based on the lecture content it makes students to apply the lecture content, informing the teacher how they have understood. Time: 3 minutes for solving, 1-3 minutes to answer questions.

- Pair and discuss - students pair off and discuss an open ended question, in order to apply, analyse or evaluate the lecture material and synthesise it with the course material. Time: 3-10 minutes, plus 5 -10 minutes for discussion.

- Think-pair-share - teacher gives students a question or a problem and asks them to think quietly, then to discuss with their neighbour and finally to share with the class.

- Students' team achievement divisions - students' teams receive a worksheet to discuss, complete and give oral presentation on results to others.

- Send a problem - each group of students write a question or a problem on a flashcard and write a right answer or a solution on the back. The card is passed to other groups which formulate their own answers and check them against that written on the back side, and write their alternative answers if necessary. At the end the original senders discuss alternative answers.

- The one-minute paper - students summarize the most important or useful points they learned from the lecture and questions that remained. It helps students think, absorb, digest, extrapolate and internalise new material moving it to long-term memory.

- The muddiest point - students give a quick response to a question: "What was not clear or confusing point in the lecture or topic?” They must identify and formulate what they did not understand. This method requires some higher-order thinking skills, ability to concentrate and pay attention.

- One-sentence summary - students summarise the lecture or topic, thus developing abilities to synthesise, summarise and integrate ideas and information.

- Directed paraphrasing - develop students' ability to translate highly specialised information into everyday language paraphrasing a lesson compactly in their own words.

It is recommended to get the class to form teams of 2-4 and choose team recorders, task managers and harmonisers. Give teams up to 3 minutes to:

- Recall prior material.

- Answer or generate a question.

- Start a problem solution or analysis.

- Work out the next step.

- Think of an example or application.

- Explain a concept in own words.

- Figure out why a predicted outcome turned out to be wrong.

- Summarise a lecture.

Professors should call on several team responses first and then take responses from volunteers. This method 
always works, as usually students are afraid of giving wrong answers individually.

At times a technical teacher may need to have students memorise information or master well-defined performance skills explicit teaching is used in the described study programme for technical teachers. It involves direct instruction methods (interactive lecture, practice, tutorials, handouts, assigned questions etc) and has high levels of student time on task. Goals and outcomes are made clear to students and sufficient time for instruction and extensive enough content coverage should occur. Careful monitoring of progress and appropriate pacing is carried out, and didactic questioning and feedback are used. The major features of explicit instruction are providing guidance during initial practice, providing practice after each step, and thus ensuring a high level of success. The explicit instruction should not be rigid and edifies students to observe, activate prior knowledge, construct meaning, monitor their understanding, organize and relate ideas, summarise and extend meaning. When possible, interactive approaches are used. At ECEP interactive lectures are of high popularity among students.

\section{CONCLUSIONS}

In order to educate not reactors to changes but, first and foremost, directors and executors of changes, it is important to promote the development of corresponding attitudes and skills in engineering students. These skills and attitudes are developed with the support of school, the key person being a teacher. Without changing teacher education we cannot bring about changes in the overall educational system.

A technical teacher needs to possess skills in at least two distinct areas: an engineering discipline and the art of teaching. A good teacher balances these two areas. As the practice of the ECEP shows, there is a wide interest towards the new courses and the interest will remain high as there are no other appropriate courses in Estonia today.

Teaching and learning engineering demands superior teaching competencies of educators. The subjects comprise specialist theory in the respective field, laboratory work and practical training in the workshop; these can be high-achieving learning environments for all students, where the most advanced curriculum and instruction techniques combine to support learning.

The point of taking account of different learning styles in teaching engineering is not to determine each student's preferred instructional approach and teach exclusively in that manner. It is rather to "teach around the cycle," making sure that every style is addressed to some extent in the instruction. If this is done, all students will be taught in a manner that addresses their preferences part of the time, keeping them from becoming so uncomfortable that they cannot learn, and requires them to function in their less preferred modes part of the time, helping them to develop skills in those modes. At ECEP, Felder-Silverman learning and teaching style model for engineering education is used as the basis for the instructional design.

Technical teachers are usually highly qualified in the field they work in, they have enough experience which enriches their lessons, are able to provide students with practical examples. But they often lack education in the teaching profession. These and other factors have led to establishing education in this field. A highly specialized person often concentrates on the topic not taking account of the basic rules and principles necessary to be applied in all phases of the educational process, starting with handing on information to students, practicing and testing new knowledge, motivating students during the whole process, choosing appropriate methods and forms etc. Each of these phases contributes to the whole process in a special way - none of them may be omitted. If so, it influences the quality of students' knowledge.

Professional technical teachers develop their science by using carefully-planned, fine-tuned lessons that reflect an understanding of many different teaching techniques. They develop artistry by being aware of what they are doing, and how it affects their learners. Professional-level teaching is both an art and a science.

\section{REFERENCES}

[1] J. Heywood, Engineering Education, Research and Development in Curriculum and Instruction, John Wiley \& Sons Inc., New Jersey, USA, 2009.

[2] K.A. Kiewra, “Teaching how to Learn” The Teacher's Guide to Student Success”,Corwin Press: SAGE, 2009.

[3] R.M. Felder, "Teaching Engineering in the 21st Century with a 12th-Century Model: How Bright is that?” Chemical Engineering Education, 40(2), 110-113, 2006.

[4] M.J. Prince, R.M. Felder. Inductive Teaching and Learning Methods: Definitions, Comparisons, and Research Bases, Journal of Engineering Education, 95(2), 123-138, 2006. http://dx.doi.org/10.1002/j.2168-9830.2006.tb00884.x

[5] R.M. Felder Richard, L.K. Silverman, Learning and Teaching Styles in Engineering Education, Engineering Education, 78(7), 674-681, 1988.

[6] R.M. Felder, R. Brent, Understanding Students Differences, Journal of Engineering Education, 94(1), 57-72, 2005. http://dx.doi.org/10.1002/j.2168-9830.2005.tb00829.x

[7] R.M. Felder, Reaching the Second Tier: Learning and Teaching Styles in College Science Education, J. College Science Teaching, 23(5), 286-290, 1993.

[8] R.M. Felder Richard, B.A. Soloman, Learning Styles and Strategies, http://www4.ncsu.edu/unity/lockers/users/f/felder/public/ILS dir/styles.htm (Retrieved February 10, 2009).

[9] T. Rüütmann, Contemporary Teaching Methods as the Basis of the Curriculum for Technical Teacher Training at Tallinn University of Technology. In: 38th IGIP Symposium - Quality and Quantity of Engineering Education, Graz, Austria, 139 - 142, 2009.

[10] P.R. Burden, D.M. Byrd, Methods for Effective Teaching Meeting the Needs of All Students, $5^{\text {th }}$ edition, Pearson education Inc., 2010.

[11] L.B. Nilson, Teaching at Its Best, A Research-Based Resource for College Instructors, Anker Publishing Company, 2003.

\section{AUTHORS}

Tiia Rüütmann is Associate Professor, Head of Estonian Centre for Engineering Pedagogy at Tallinn University of Technology, Ehitajate tee 5, 19086, Tallinn, Estonia (e-mail: tiia.ruutmann@ttu.ee), Member of IGIP EC.

Hants Kipper is a Lecturer at Estonian Centre for Engineering Pedagogy at Tallinn University of Technology, Ehitajate tee 5, 19086, Tallinn, Estonia (e-mail: hants.kipper@ttu.ee ), Member of IGP IMC.

This article is an extended and modified version of a paper presented at the IGIP2012 conference, held 26 - 28 September 2012, in Villach, Austria. Received 30 November 2012. Published as resubmitted by the authors 18 December 2012. 